\title{
EDITORIAL
}

\section{In This Issue: Systematic Strategies and Individualized Approaches to Care}

\author{
Elizabeth A. Bayliss, MS, MSPH, Associate Editor
}

Ann Fam Med 2009;7:290-291. doi:10.1370/afm.1019.

$\mathrm{T}$ his issue features several articles that explore different strategies to improve the care of patients with chronic conditions. The varied contexts in which we deliver primary care provide a range of opportunities for systematic interventions. Such systematic changes, complemented by the strengths within our local settings, may help us to creatively expand our own individual approaches to care delivery.

\section{SYSTEMS-LEVEL STRATEGIES}

In a study set in Ontario, Russell and colleagues ${ }^{1}$ investigated whether chronic disease management differed between 4 models of primary care delivery, and which practice organizational factors were independently associated with higher quality chronic disease management.They found that chronic disease management was superior in community health centers-clinicians in these settings reported longer consultations and interprofessional collaboration. In addition, use of a nursepractitioner was associated with higher-quality and increased patient load and larger practices were associated with lower-quality chronic disease management.

Goldberg et $\mathrm{al}^{2}$ used a survey to assess existing components of the recommended practice model of the patient-centered medical home in family medicine offices in Virginia. While most practices included some components of the model, full implementation was low. They discuss the importance of considering practice characteristics and challenges when developing policies for care model reform.

\section{PATIENT- AND PRACTICE-LEVEL STRATEGIES}

Much of ongoing chronic disease management (as well as the management of acute illness) depends on systematic processes to manage test results. ${ }^{3,4}$ In a qualitative analysis, Elder et al studied the management of test results in 4 separate practices. ${ }^{5}$ They note wide variability in the establishment of, and adherence to, systems for results management. Even so, they identify safety awareness and technological adoption as themes that may guide practices in assessing processes for results management.

Jerant et al conducted a randomized controlled trial to investigate the effect of home- and telephonebased peer-led chronic illness self-management training programs on quality of life and utilization outcomes by improving patient self-efficacy. ${ }^{6}$ Although the home-based intervention improved self-efficacy in the short term, there was limited effect on quality of life at 1 year and no effect on utilization. The telephone-based program did not yield significant effects. While acknowledging that disease-based self-efficacy is important, these results do not encourage a systematic implementation of these methods of peer-led self-management.

The foundation of effective interventions to improve care depends, in part, on our ability to define populations at risk for poor health outcomes, make accurate diagnoses, and couple these with relevant health outcomes. ${ }^{7}$ In an article on the implications of comorbid chronic medical conditions, Valderas and colleagues discuss the importance of defining the multiple terms used to characterize patients with multiple morbidities and emphasize that accurate terminology will guide discussions within epidemiology, clinical care, and health policy. ${ }^{8}$ In another assessment of comorbid conditions, $\mathrm{O}^{\prime}$ Connor et al challenge the belief that persons with diabetes are at risk for incident depression. ${ }^{9}$ They report that an observed risk for new depression in this population disappeared when adjusted for exposure to the medical system.

From an outcomes perspective, Hahn concludes that the new expert panel report on the management of asthma exemplifies guidelines are limited by a flawed evidence-grading system. They believe that the guidelines could be enhanced by more attention to applicable patient populations, patient-oriented outcomes, and shared decision making to improve health outcomes. ${ }^{10}$ 


\section{THE RISKS OF OBESITY}

Obesity is a public health epidemic that affects health at all ages. Researchers in the Netherlands assessed the impact of obesity in the pediatric population. In a cross-sectional assessment of the association between childhood obesity and musculoskeletal problems, Krul et $\mathrm{a}^{11}$ note that overweight and obese children in both younger and older age-groups reported more musculoskeletal complaints than did normal weight children.

\section{CULTIVATING AND PRACTICING THE ART OF MEDICINE}

In a glimpse at the professional aspirations, commitments, and values that medical students consider in developing their own professional identities, Rabow and colleagues ${ }^{12}$ present a thematic analysis of individual mission statements written by a range of medical students. Three primary themes of professional skills, personal qualities, and scope of professional practice emerged from comments on such topics as dealing with fears, personal-professional balance, love, relationships, self-care, and healing. The authors encourage creative use of medical school curricula to cultivate these insights and aspirations in the next generation of clinicians.

In the third installment of an editorial series, Stange and Ferrer explore the paradox of primary care and the added value of integrating generalist and specialist care to better care for the whole person. ${ }^{13}$

To read or post commentaries in response to this article, see it online at http://www.annfammed.org/cgi/content/full/7/4/290.

\section{References}

1. Russell GM, Dahrouge S, Hogg W, Geneau R, Muldoon L, Tuna M. Managing chronic disease in Ontario primary care: the impact of organizational factors. Ann Fam Med. 2009;7(4):309-318.

2. Goldberg DGG, Kuzel AJ. Elements of the patient-centered medical home in family practices in Virginia. Ann Fam Med. 2009; 7(4):301-308

3. Poon EG, Gandhi TK, Sequist TD, Murff HJ, Karson AS, Bates DW. "I wish I had seen this test result earler!" Dissatisfaction with test restul management systems in primary care. Arch Intern Med. 2004;164:2223-2228.

4. Smith PC, Araya-Guerra R, Bublitz C, et al. Missing clinical information during primary care visits. JAMA. 2005;293:565-571.

5. Elder NC, McEwen TR, Flach JM, Gallimore JJ. Management of test results in family medicine offices. Ann Fam Med. 2009;7(4):343-351.

6. Jerant A, Moore-Hill M, Franks P. Home-based, peer-led chronic illness self-management training: findings from a 1-year randomized controlled trial. Ann Fam Med. 2009;7(4):319-327.

7. Schunemann HJ, Oxman AD, Brozek J, et al. GRADE: Assessing the quality of evidence for diagnostic recommendations. ACP J Club. 2008;149(6):2.

8. Valderas JM, Starfield B, Sibbald B, Salisbury C, Roland M. Defining comorbidity: implications for understanding health and health services. Ann Fam Med. 2009;7(4):357-363.

9. O'Connor PJ, Crain AL, Rush WA, Hanson AM, Fischer LR, Kluznik JC. Does diabetes double the risk of depression? Ann Fam Med. 2009;7(4):328-335.

10. Hahn DL. Importance of evidence grading for guideline implementation: the example of asthma. Ann Fam Med. 2009;7(4):364-369.

11. Krul M, van der Wouden JC, Schellevis FG, van Suijlekom-Smit LWA Koes BW. Musculoskeletal problems in overweight and obese children. Ann Fam Med. 2009;7(4):352-356.

12. Rabow MW, Wrubel J, Remen RN. Promise of professionalism: personal mission statements among a national cohort of medical students. Ann Fam Med. 2009;7(4):336-342.

13. Stange KC, Ferrer RL. The paradox of primary care. Ann Fam Med. 2009;7(4):293-299. 